\title{
Health Impact of and Policy Regulations on Electronic Cigarettes
}

\author{
Hilton Y. Lam, ${ }^{1}$ Carlo Irwin A. Panelo, ${ }^{2}$ Ofelia P. Saniel, ${ }^{3}$ Carmelita C. Canila, ${ }^{4}$ \\ Jonathan P. Guevarra, ${ }^{5}$ Ma-Ann M. Zarsuelo ${ }^{6}$ and Ma. Angelica Q. Castro ${ }^{6}$ \\ ${ }^{1}$ Institute of Health Policy and Development Studies, National Institutes of Health, University of the Philippines Manila \\ ${ }^{2}$ Department of Clinical Epidemiology, College of Medicine, University of the Philippines Manila \\ ${ }^{3}$ Department of Epidemiology and Biostatistics, College of Public Health, University of the Philippines Manila \\ ${ }^{4}$ Department of Health Policy and Administration, College of Public Health, University of the Philippines Manila \\ ${ }^{5}$ Department of Health Promotion and Education, College of Public Health, University of the Philippines Manila \\ ${ }^{6}$ University of the Philippines Manila Health Policy Development Hub
}

\begin{abstract}
Background. New findings on the detrimental health effects of electronic nicotine delivery system (ENDS)/ electronic non-nicotine delivery system (ENNDS) confounds the "harm reduction" perspective of using it as an alternative to conventional cigarettes. In the Philippines, the pressing debate on its safety and efficacy had initiated actions from policy makers on legislative issues such as draft DOH Administrative Order, House Bill 4325 and House Bill 532.
\end{abstract}

Objective. The study aimed to craft an evidence-based policy position on the regulation of ENDS/ENNDS.

Method. Review of literature was conducted, and the proposed scope and measures on electronic cigarette regulation were compared with WHO Framework Convention on Tobacco Control (WHO-FCTC) and existing policies of US FDA regulations on ENDS. Further, UP Manila convened experts of various related fields for evidence-based review and discussion of policy issues to arrive at a consensus policy statement and recommendations.

Results. Findings showed that ENDS/ENNDS still need further research to have conclusive results on long term safety and efficacy as smoking cessation methods.

Conclusion. Regulations for tobacco control should be clear and supported with strict guidelines in manufacturing, distribution, advertisement, selling, and usage restrictions in public. With the current review, it is recommended that ENDS/ENNDS regulation be under the mandate of the FDA in alignment to WHO-FCTC and to engage different stakeholders from policy makers, implementers, and other involved organizations.

Key Words: Electronic nicotine delivery system (ENDS), Electronic non-nicotine delivery system (ENNDS), Regulation policies

\section{INTRODUCTION}

Corresponding author: Hilton Y. Lam, MHA, PhD Institute of Health Policy and Development Studies National Institutes of Health

University of the Philippines Manila

623 Pedro Gil Street, Ermita, Manila 1000, Philippines

Telefax: +6323543832

E-mail: hiltonlam2018@gmail.com
The proven detrimental health effects of tobacco smoking paved the way for electronic cigarettes (EC) to enter the market. Sale of EC started via online stores in China, and now major international tobacco companies have launched their own brands. ${ }^{1}$ Electronic cigarettes penetrated the European market in 2005 and had a sharp increase in annual demand owing to advertisements portraying EC as a healthy cigarette alternative and smoking cessation tool. ${ }^{2}$ The global market of Electronic Nicotine Delivery System (ENDS)/Electronic Non-Nicotine Delivery System (ENNDS) was estimated to be US\$ 10 billion in 2015. Majority of sales (56\%) was attributed to the United States of America, $12 \%$ to the United Kingdom, 7\% each for China, France, and Germany, and 3\% each for Italy 
and Poland. Internet sales accounted for one-third of the worldwide market in 2014, with the largest market share in the regions of Latin America, Australasia, and Asia Pacific. ${ }^{3}$

In the Philippines, the increase of EC market is parallel with the pressing debate on its safety and efficacy, and thus requiring the attention of the Philippine Food and Drug Administration (FDA) and legislators. In April 2013, Philippine FDA Advisory No. 2013-008 warned that beneficial claims as well as possible health consequences from EC have not been established and needed further research. ${ }^{4}$ This stirred opposing views between health advocates and ENDS stakeholders including the Philippine E-cigarette Industry Association (PECIA) which is composed of manufacturers, store owners, and suppliers of ENDS and related products in the country with the aim to set forth best practice standards and serve as the self-regulatory body of this new market. With the growing concerns, the FDA conducted public hearings in July and December 2013 to discuss the views of the public and stakeholders. Towards the end of 2013, the Department of Health (DOH) drafted an Administrative Order (AO) on the Guidelines on the Regulation of Electronic Nicotine Delivery System (ENDS) or Electronic Cigarettes as a Manufactured Product. In 2016, House Bills 4325 and 532 were proposed in order to regulate EC. In 2017, the President issued Executive Order 26 imposing a nationwide ban on smoking, however, EC were excluded. The DOH Secretary explained that the inclusion of ENDS in the smoking ban will be considered when there is enough evidence and a recommendation from the $\mathrm{WHO}$ is issued. ${ }^{5}$

\section{REVIEW OF LITERATURE}

\section{A. Description of ENDS/ENNDS}

The World Health Organization Tobacco Free Initiative (WHO-TFI) defines EC as "devices that do not burn or use tobacco leaves but instead a solution that the user then inhales." "EC" is the generic term used to include both ENDS and ENNDS. All ENDS/ENNDS heat a solution to create an aerosol which frequently contains flavorants, propylene glycol, or/and glycerin. All ENDS contain nicotine but ENNDS do not. ${ }^{6}$

Consumer satisfaction of ENDS/ENNDS are said to be derived from its efficiency in mimicking the sensory feel of conventional smoking. This is directly affected by the choice of vapor liquid, puffing style, and the device's capacity to aerosolize the liquid. ${ }^{3}$

\section{B. Health impact}

Since ENDS/ENNDS were only introduced to the market in 2006, only short to medium-term studies on its adverse effects are available. Evidences on long-term health effects remain lacking.

According to WHO-FCTC, using ENDS/ENNDS "produces aerosol that ordinarily includes glycols, aldehydes, volatile organic compounds (VOCs), polycyclic aromatic hydrocarbon (PAHs), tobacco-specific nitrosamines (TSNAs), metals, silicate particles, and other elements. Dicarbonyls (glyoxal, methylglyoxal, diacethyl) and hydroxycarbonyls (acetol) also are thought to be important compounds in the aerosol." Most of these toxicants have known ranges of health consequences. ${ }^{7}$

A systematic review in 2016 shows that the safety of ENDS/ENNDS in the long-term is unknown. Although there were no reported serious adverse effects considered related to ENDS/ENNDS use, the most common adverse effects observed were irritation of the mouth and throat. ${ }^{8}$ However, another study reported negative effects from use or exposure to ENDS/ENNDS and refill fluid such as 1) systemic effects including respiratory, gastrointestinal, neurological, cardiovascular, and immune irritation and responses; 2) nicotine poisoning; and 3) mechanical injury. ${ }^{9}$

\section{Nicotine}

Nicotine is the addictive tobacco component that is already an established contributor in cardiovascular diseases and have an impact on cognitive performance. ${ }^{1,7}$ In terms of ENDS, several studies show large variability on nicotine concentrations across brands, labels, and cartridges. Some studies show that short-term use results to increased heartrate and elevation of diastolic blood pressure, while other studies show otherwise. ${ }^{1}$ Caution must still be taken by vulnerable groups (i.e. children, adolescent, pregnant women, women of child-bearing age) from nicotine exposure due to potential long-term consequences in brain development. ${ }^{7}$

The increased potential for accidental poisoning can be attributed to the easy access and availability of refill juice with high nicotine content, lack of or inaccurate labeling, and different flavors including candy and confectionery-like aromas that appeal to children. The lack of regulation on ENDS places at risk not only adults but also children, who model the behavior of adults, and teenagers who tend to use ENDS for social status and social acceptance. ${ }^{10}$

Although nicotine is addictive and has a range of local irritant effects, it is not a carcinogen. Lung cancer arises primarily from exposure to carcinogens in tobacco smoke. ${ }^{11}$ However, it was identified in the WHO-FCTC (2016) that given the chemical compounds in the liquids for ENDS/ ENNDS aerosol: 1) there is potential cytotoxicity of solutions on pregnant women; 2) solid evidence from different research methods are still needed to be certain on potential adverse health effects; and 3) there are no agreed upon tolerance limits for smoke constituents. ${ }^{3}$

\section{Mechanical Injury}

There are few case reports related to EC battery explosions leading to multiple injuries. There were two reported cases of corneal injury, one oral burn due to explosion while using $\mathrm{EC}$, and one leg burn from spontaneous explosion while EC was not in use. ${ }^{9,12}$ While 
there are no published studies from the Philippines, online media reported a case of EC explosion during a trial use in a store. The few reports may mask the significant public health risk since similar incidents continue to appear in online media reports in different countries. Therefore, the actual number of cases is probably much higher than those reported.

\section{Second-hand Smoke}

In a recent systematic review, it was found that the second-hand aerosol (SHA) from ENDS/ENNDS has the potential to lead to adverse health effects. SHA from ENDS aerosol contain lower levels of nicotine and toxicants, except for metals such as nickel and chromium, compared to secondhand smoke (SHS) from conventional burning cigarettes. However, compared to background air level, nicotine in SHA is found to be 10 to 115 times higher, acetaldehyde between two to eight times higher, and formaldehyde about $20 \%$ higher. $^{3}$

The WHO-FCTC report in 2016 stated that "while some argue that exposure to SHA is unlikely to cause significant health risks, they concede that SHA can be deleterious to bystanders with some respiratory pre-conditions". The substances from the emission also accumulate in indoor air and may lead to harmful second-hand exposure. ${ }^{4}$

\section{Efficacy on Smoking Cessation}

There is some evidence (low in GRADE System) that EC may help smokers to quit smoking in the long term compared to placebo EC. ${ }^{8}$ Electronic cigarettes address the behavioral aspects of smoking (holding cigarette, enjoyment of smoking, and puffing) more than nicotine patches and other behavioral support, hence, more effective in smoking cessation. However, a recent cross-sectional study shows that on a population level, EC were not effective in helping smokers quit smoking conventional cigarettes in EU (and Great Britain) as smokers are more likely to completely switch to ENDS rather than fully quit smoking, therefore, leading to dual use of ENDS and conventional cigarettes. ${ }^{13}$ The "harm reduction" strategy of using EC might be beneficial only to smokers who are reluctant to quit, but not for the ex- and non-smokers. ${ }^{1,7}$

\section{Regulation}

The DOH-FDA released a statement that they have not registered any EC products. At present, there is no government regulatory agency on EC in the Philippines. Hence, the following policy instruments are compared: (1) House Bill 532 (An Act Regulating the Packaging, Use, Sale, Distribution, and Advertisement of Electronic Smoking Devices, Amending for the Purpose of RA 9211) ${ }^{14}$; (2) House Bill 4325 (An Act Regulating the Manufacture, Distribution, Sale, Importation and Use of Electronic Cigarette in the Philippines) ${ }^{15}$; (3) draft Administrative Order by DOH (Guidelines on the Regulation of Electronic Nicotine Delivery
System (ENDS) or Electronic Cigarettes as a Manufactured Product) in $2013^{16}$; (4) US FDA regulations on $\mathrm{ENDS}^{17}$; (5) European Tobacco Products Directive (EU-TPD) ${ }^{18}$; and (6) World Health Organization Framework Convention on Tobacco Control (WHO-FCTC) 2016 regulation options on ENDS/ENNDS 3 .

In the USA, the FDA has the authority to regulate all commercial processes of EC since they were classified as tobacco products since 2016. In contrast, the draft DOH AO classified EC as a medicinal product instead of as a tobacco product. On the other hand, House Bill 4325 only provided that the manufacture and distribution of $\mathrm{EC}$ will be regulated by the FDA, with the $\mathrm{DOH}$ as the implementing agency for rules and regulations.

\section{Quality Assurance}

Based on the draft $\mathrm{DOH} \mathrm{AO}$, guidelines on claiming beneficial effects (cessation aid, etc.), ingredients, and cartridge design shall be strictly implemented to ensure that products meet quality standards. WHO-FCTC added that toxicological compounds should be banned/restricted while electrical safety should be monitored. In the UK, regulation of END/ENNDS is specific as to the nicotine amount where cartridges containing $0-20 \mathrm{mg} / \mathrm{mlare}$ under EU Tobacco Directive (EU-TPD) while cartridges with higher nicotine levels are regulated by the EU's Medicines and Healthcare Products Regulatory Agency (MHRA).

\section{Manufacturing and Distributing}

The US FDA clearly specifies that all manufacturers, distributors, and retailers of EC and EC-related products are subject to regulation. This is not specified in the draft $\mathrm{DOH}$ $\mathrm{AO}$ since only the Certificate of Product Registration (CPR) and License to Operate (LTO) are mentioned. Meanwhile, House Bill 4325 only includes provisions on registration of manufacturers with no specific requirements for compliance. Nevertheless, both USA and Philippine FDA guidelines require the manufacturers to meet the standards of current Good Manufacturing Practice (cGMP).

\section{Selling and Advertising}

Parameters on prohibiting access to minors and clear bold health warning statements in EC packages and advertisement are mentioned in the US FDA guidelines on ENDS, Philippine House Bills 4325 and 532, EU-TPD, and WHO-FCTC. Furthermore, in the draft DOH AO, FDA is tasked to conduct post-market surveillance and regulate the advertisement, promotion of the product, and the marketing activities of the establishment after the CPR has been issued.

\section{Impacts on the Environment}

In the draft DOH AO, FDA will not allow the use of electronic cigarettes in public areas or in areas and facilities that prohibit smoking. In the UK, Public Health England (2016) published proposed set of guidelines for smoking in 
public places that are based on five principles: 1) make clear distinction between vaping and smoking; 2) ensure policies are informed by the evidence on health risks to bystanders; 3 ) identify and manage risks of uptake by children and young people; 4) support smokers to stop smoking and stay smoke-free; and 5) support compliance with smoke-free law and policies.

\section{Terms with Tobacco Industry}

House Bill 532 prohibits sponsorship of any companies engaged in production, manufacture, and distribution of cigarette, tobacco, or electronic smoking devices in any public or private events that includes advertisement or promotion of such company. In addition to this, WHOFCTC includes stricter guidelines, further limiting the participation and partnership of tobacco industry with other stakeholders (public or private) and related activities with the interest of promotion.

Levy and colleagues (2016) suggest discouraging cigarette use but providing means for smokers to quit by creating policies that aim to discourage use of vaporized nicotine products (VNP) by never smokers, while encouraging innovations in VNP products that are proven to support smoking cessation as there is a "strong potential for VNP use to improve population health by reducing or displacing cigarette use in countries where cigarette use is high and smokers are interested in quitting." ${ }^{19}$

\section{METHODS}

Review of literature was conducted, and the proposed scope and measures on electronic cigarette regulation were compared with WHO Framework Convention on Tobacco Control (WHO-FCTC) and existing policies of US FDA regulations on ENDS.

Further, UP Manila convened experts of various related fields for evidence-based review and discussion of policy issues to arrive at a consensus policy statement and recommendations.

\section{RESULTS AND DISCUSSION}

Key findings from the current review shows that ENDS/ENNDS are claimed to emit less toxic substances compared to burning tobacco. However, the contents of cartridges vary widely as do their potential health effects. There are documented short term adverse effects on its usage but long term safety and health risk studies are still inconclusive. Evidences from studies in different countries on the use of ENDS/ENNDS as a smoking-cessation method remains limited and mixed. Aside from the posed health risk among the users, another population of concern are those exposed to second-hand aerosol, particularly the vulnerable groups, and those with respiratory pre-conditions who are potentially at risk.
With its increasing demand in the market, initiatives from international organizations are establishing guidelines on its regulation. Commitment on its safe and monitored manufacturing, distribution, advertisement, and selling are starting to be evident on the emerging and existing regulatory government policies globally. Currently, regulatory measures for ENDS/ENNDS vary across countries.

\section{RECOMMENDATIONS}

Given the evidence-based safety and health risks of ENDS/ENNDS and the regulatory policies identified and practiced across countries, the following are recommended:

1. The use of ENDS/ENNDS should be regulated in terms of its manufacture, distribution, sale and use, and even its advertisements.

2. Regulation of ENDS/ENNDS can be done under the mandate of the FDA. For example, the use of ENDS as a smoking cessation method should be done under medical supervision only. Never smokers should not be allowed to use ENDS/ENNDS.

3. Further research is needed to establish the long-term safety and health effects of ENDS/ENNDS.

4. Implementing agency should revisit our country commitment to the WHO- FCTC, to which we were a signatory in 2006.

5. Government must require licenses for all suppliers and manufacturers of ENDS within the country and utilize e-commerce laws to regulate internet sales of ENDS.

6. Government should counter misleading information in advertising and promotional materials in the internet and other media by providing balanced information and enforcing consumer protection laws.

7. Since the government has already implemented graphic warnings in cigarettes, there must be safety seals approved by the government. This is in recognition of the fact that e-liquids are already widely available in the market, including through online access. To protect consumers and the public from exposure to dangerous substances contained in ENDS/ENNDS, the government should develop strict measures to limit the availability of and require proper marking of any liquid that contains propylene glycol, a key ingredient in most e-liquids.

8. The government, to regulate ENDS/ENNDS, must develop its capacity to test samples of a wide array of e-liquids.

9. Prevent the proliferation of EC in different outlets/ stores by restricting access or accrediting/ licensing retailers in addition to a rigorous approval process.

10. Engage civil society organizations in monitoring ENDS/ENNDS in the market.

11. To be consistent with the country's enforcement of No Smoking in Public Places, the government must ban use of e-cigarette in public places for the protection of the 
general public, particularly, protection from second-hand smoke (particularly against particulate toxins that can enter the lungs) and prevention of further youth uptake.

12. There should be more focused research to improve ENDS/ENNDS as a smoking cessation tool for heavy smokers or smokers who wish to quit.

\section{Acknowledgement}

The authors express their sincere gratitude to the Office of the Chancellor of the University of the Philippines Manila and the National Institutes of Health for their support and wisdom in this endeavor.

\section{Statement of Authorship}

All authors have approved the final version submitted.

\section{Author Disclosure}

All the authors declared no conflicts of interest.

\section{Funding Source}

No external funding.

\section{REFERENCES}

1. Pisinger C, Dossing M. A systematic review of health effects of electronic cigarettes. Preventive Medicine. 2014; 69:248-60.https:// doi.org/10.1016/j.ypmed.2014.10.009.

2. Geiss O, Bianchi I, Barahona F, Barrero-Moreno J. Characterisation of mainstream and passive vapours emitted by selected electronic cigarettes. Int J Hyg Environ Health. 2015; 218 (1): 169-80.https:// doi.org/10.1016/j.ijheh.2014.10.001.

3. World Health Organization Framework Convention on Tobacco Control. 7th Conference of the Parties Report. Delhi, India. 2016.

4. Food and Drug Administration Philippines. Electronic Cigarettes and R.A. No. 9211, Otherwise Known as the Tobacco Act of 2003, FDA Advisory No. 2013-008 [Online]. 2013 [cited 2018 February]. Available from http://www.fda.gov.ph/advisories/food/38692-fdaadvisory-no-2013-08.

5. Executive Order No 26.Providing for the Establishment of SmokeFree Environments in Public and Enclosed Places. 2017.

6. World Health Organization Tobacco Free Initiative. Electronic Nicotine Delivery Systems and Electronic Non-Nicotine Delivery Systems (ENDS/ENNDS) [Online]. 2017 [cited 2018 February]. Available from http://www.who.int/tobacco/communications/ statements/eletronic-cigarettes-january-2017/en/.
7. World Health Organization Framework Convention on Tobacco Control. 6th Conference of the Parties Report. Moscow, Russian Federation. 2014.

8. Hartmann-Boyce J, McRobbie H, Bullen C, Begh R, Stead LF, Hajek P. Cochrane Review: Electronic cigarettes for smoking cessation (Review). 2016

9. Hua M, Talbot P. Potential health effects of electronic cigarettes: A systematic review of case reports. Preventive Medicine Reports. 2016; 4: 169-78.https://doi.org/10.1016/j.pmedr.2016.06.002.

10. American Academy of Pediatric Dentistry. Policy on Electronic Cigarettes [Online]. 2015 [cited 2018 February]. Available from http://www.aapd.org/media/Policies_Guidelines/P_ElectronicCig. pdf.

11. Royal College of Physicians Tobacco Advisory Group. Nicotine without smoke Tobacco harm reduction: A report by the Tobacco Advisory Group of the Royal College of Physicians. The Lavenham Press, Suffolk, Great Britain. 2016.

12. Paley GL, EchalierE, Eck TW, Hong AR, Farooq AV, Gregory DG, Lubniewski AJ. Corneoscleral Laceration and Ocular Burns Caused by Electronic Cigarette Explosions. Cornea. 2016 Jul; 35(7): 1015-8.

13. Kulik M, Lisha N, Glantz S. E-cigarettes associated with depressed smoking cessation: A cross-sectional study of 28 European Union Countries. Am J Prev Med. 2018;54(4):603-609.

14. House Bill No 532. An Act Regulating the Packaging, Use, Sale, Distribution, and Advertisements of Electronic Smoking Devices, Amending for the Purpose Republic Act No. 9211, Otherwise Known as the Tobacco Regulation Act of 2003, and for Other Purposes, House Bill No 532,17th Congress, 1st Session. 2016.

15. House Bill No 4325. An Act Regulating the Manufacture, Distribution, Sale, Importation and Use of Electronic Cigarettes in the Philippines, House Bill No 4325, 17th Congress 1st Session. 2016.

16. Department of Health. Guidelines on the Regulation of Electronic Nicotine Delivery System (ENDS) or Electronic Cigarettes as a Manufactured Product. Draft Administrative Order, 2013 [Online]. 2013 [cited 2018 February]. Available from http://www.fda.gov. $\mathrm{ph} /$ drafts-for-comments/125047-guidelines-on-the-regulation-ofelectronic-nicotine-delivery-system-ends-or-electronic-cigarettes-asa-manufactured-product.

17. US Food and Drug Administration. Vaporizers, E-cigarettes, and other Electronic Nicotine Delivery System (ENDS) [Online]. 2018 [cited 2018 February]. Available from https://www.fda.gov/ TobaccoProducts/Labeling/ProductsIngredientsComponents/ ucm 456610.htm\#regulation.

18. European Commission. Revision of tobacco products derivative. 2014.

19. Levy DT, Cummings KM, Villanti AC, Niaura R, Abrams DB, Fong GT, Borland R. A framework for evaluating the public health impact of e-cigarettes and other vaporized nicotine products. Addiction. 2017 Jan; 112(1): 8-17. 